\title{
Sequential MRI, Cerebrospinal Fluid and Peripheral Blood Immunologic Analysis in a Natalizumab-Treated Patient With Progressive Multifocal Leukoencephalopathy
}

\author{
Clara de Andres ${ }^{\mathrm{a}, ~ e}$, Barbara Alonso $^{\mathrm{b}}$, Juan Guzman de Villoria ${ }^{\mathrm{c}}$, Rosa Peraita-Adrados ${ }^{\mathrm{d}}$, \\ Silvia Sanchez-Ramon ${ }^{\mathrm{b}}$
}

\begin{abstract}
We report a natalizumab (NTZ)-treated relapsing-remitting multiple sclerosis (RRMS) patient evaluated for worsening of pyramidal and cerebellar dysfunction. MRI showed $\mathrm{Gd}^{+}$lesions in juxtacortical frontal areas and middle cerebellar peduncles indicative of progressive multifocal leukoencephalopathy (PML). Cerebrospinal fluid (CSF) showed $47 \mathrm{JC}$ virus (JCV) copies/mL, high $\mathrm{CD}^{+}$and plasmacytoid dendritic cells (pDCs) compared to peripheral blood (PB). MRI after NTZ discontinuation and plasma exchange revealed PML aggravation. CSF JCV increased to 475 as $\mathrm{CD}^{+}, \mathrm{CD} 19^{+}$and pDCs. CSF 8 months later showed high $\mathrm{CD}^{+}, \mathrm{CD} 19^{+}$, pDCS, not JCV. MRI showed severe focal cortical atrophy and axonal degeneration of pontocerebellar fibers. Specific immune-cell response in the central nervous system (CNS) may be essential for control of PML.
\end{abstract}

Keywords: Immune cells; Inflammatory progressive multifocal leukoencephalopathy; Multiple sclerosis; MRI; Natalizumab

\section{Introduction}

Progressive multifocal leukoencephalopathy (PML) is a rare progressive demyelinating and life-threatening infection of the central nervous system (CNS) caused by JC virus (JCV) infection [1]. Depletion of lymphocytes and impaired CNS immune surveillance are thought to be predisposing factors.

Manuscript accepted for publication February 25, 2015

aDepartment of Neurology, Hospital General Universitario Gregorio Maranon, Madrid, Spain

bepartment of Immunology, Hospital General Universitario Gregorio Maranon, Madrid, Spain

'Department of Radiology, Hospital General Universitario Gregorio Maranon, Madrid, Spain

${ }^{\mathrm{d} D e p a r t m e n t}$ of Clinical Neurophysiology, Hospital General Universitario Gregorio Maranon, Madrid, Spain

${ }^{e}$ Corresponding Author: Clara de Andres, Department of Neurology, Hospital General Universitario Gregorio Maranon, Complutense University, C/Dr. Esquerdo, 46, Madrid 28007, Spain.

Email: claradeandres@hotmail.com

doi: http://dx.doi.org/10.14740/jmc2079w
Natalizumab (NTZ) treatment is associated with an increased risk of PML, though the exact pathogenic mechanisms are still not fully understood. PML should be diagnosed as early as possible but this may sometime be difficult as the clinical presentation of PML is often similar to a multiple sclerosis (MS) relapse. Diagnosis is based on a combined analysis of clinical course, brain MRI scans, and polymerase chain reaction (PCR) of cerebrospinal fluid (CSF) for JCV.

NTZ treatment should be suspended immediately on suspicion of PML and their clearance can be accelerated by plasma exchange (PLEX) therapy [2], though re-establishment of CNS immunosurveillance is often associated with immune reconstitution inflammatory syndrome (IRIS), characterized by inflammatory changes on MRI. Information on the immune cells and mediators involved in PML is patchy. We describe the sequential clinical and radiological features of PML from onset in an NTZ-treated relapsing-remitting multiple sclerosis (RRMS) patient and provide data on CSF JCV copies and immune cell counts in CSF and peripheral blood (PB). The study was conducted at the Neurology Department of the Gregorio Maranon University Hospital (Madrid) and approved by the local ethics committee.

\section{Case Report}

We report a 47-year-old man with a 20-year history of RRMS on NTZ after failure to control disease activity with interferon beta and glatiramer acetate therapy. While on NTZ treatment (300 mg every 4 weeks for 27 months), he had remained free of disease activity (no clinical relapses and no new T2 or $\mathrm{Gd}^{+}$-enhancing $\mathrm{T} 1$ lesions) and the expanded disability status scale (EDSS) score was stable at 4.5. He was evaluated due to worsening of cerebellar and pyramidal symptoms affecting both lower limbs and left hand apraxia in the previous month (EDSS, 5.5). A cranial MRI scan was consistent with PML (Fig. A1-A4) and he was seropositive for JCV. The CSF (January 17,2012 ) revealed 75 copies $/ \mathrm{mL}$ of JCV. $\mathrm{pDCs}$ and $\mathrm{CD} 8^{+}$ $\mathrm{T}$ cells were predominant in CSF with respect to PB (Table 1), and the IgG index was 0.75 (normal $\leq 0.7$ ). NTZ was discontinued and the patient received six PLEX sessions followed by IV-IgG $0.4 \mathrm{~g} / \mathrm{kg} /$ day for 4 days.

After 6 weeks, lower limb kinetic tremor and left partial motor seizures were observed. The MRI lesions worsened 

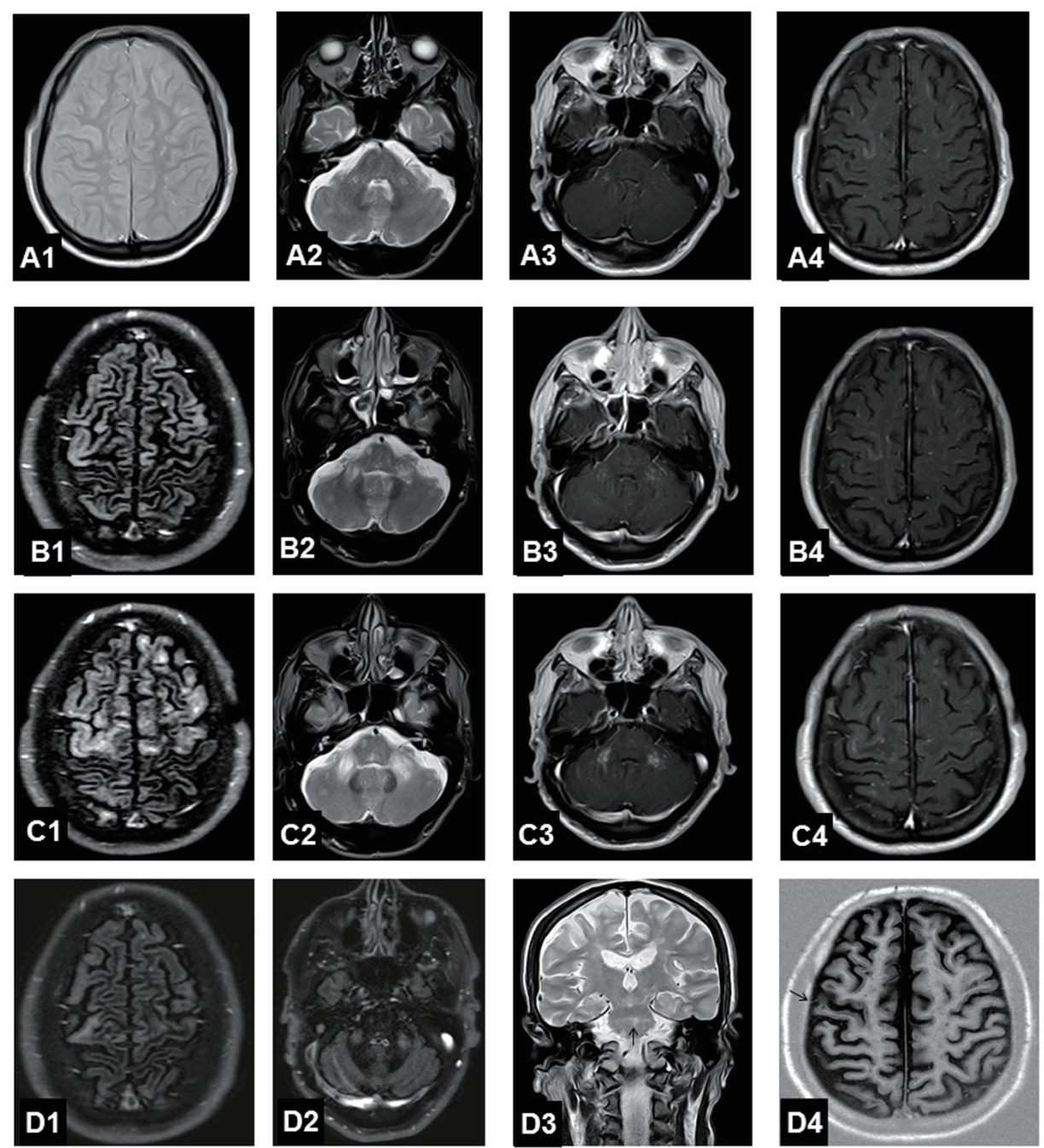

Figure 1. Serial MRI images. At baseline, axial proton-density spin-echo images showed hyperintense lesions in cortical and juxtacortical areas of the frontal lobes (A1). Abnormal hyperintensity of the middle cerebellar peduncles was also observed on axial turbo-spin-echo (TSE) T2-weighted images (A2), consistent with progressive multifocal leukoencephalopathy (PML). After administration of gadolinium, a subtle enhancement of these lesions on axial T1-weighted magnetization transfer (MT) images was observed (A3 and A4). After 6 weeks, progression of the PML lesions on axial double inversion recovery (DIR) images (B1) and TSE T2-weighted images (B2) was observed. In addition, $\mathrm{Gd}^{+}$contrast enhancement became more conspicuous on axial T1-weighted MT images (B3 and B4). In the cerebral MRI performed after 15 weeks, the hyperintense lesions on the frontal lobes and middle cerebral peduncles had enlarged, as shown on axial DIR images (C1) and on TSE T2-weighted images (C2). Worsening of these findings was more subtle in the frontal lobes (C4) than in the cerebellum (C3) by axial post-contrast T1-weighted MT images. Cerebral-MRI performed after 31 weeks showed improvement in PML lesions as shown on DIR images (D1 and D2). MRI findings suggested neurodegenerative phenomena as we observed hyperintensity of pontocerebellar fibers (arrow) on axial TSE T2-weighted images (D3) and atrophy at previous PML lesions in the cerebral hemispheres. These findings were more conspicuous in the right precentral gyrus (arrow) on T1 inversion recovery image (D4).

(Fig. B1-B2). In CSF analysis, $475 \mathrm{JCV}$ copies $/ \mathrm{mL}$ and $\mathrm{IgG}$ index of 0.56 were found. A marked CSF increase in $\mathrm{CD}^{+} \mathrm{T}$ cells and $\mathrm{CD} 19^{+} \mathrm{B}$ cells and decreased $\mathrm{CD} 8^{+} \mathrm{T}$ cells and pDCs compared with PB (February 24, 2012) were found.

MRI after 15 weeks showed worsening of the previous findings (Fig. C1-C4).

After 4 months, the patient presented a new spinal cord relapse at $\mathrm{T} 8$ level. Increase in $\mathrm{CD} 4^{+}, \mathrm{CD} 19^{+}$, and pDCs persisted in CSF compared with PB (Table 1), and the IgG index increased to 3.96 .

Eight months after onset of PML, pyramidal signs, gait ignition failure, severe proximal intention tremor in lower limbs movements, left hand apraxia, and sensory loss from T8 were present. The MRI-PML lesions (Fig. D1-D4) were suggestive of neuronal and axonal damage because of inflammatory PML lesions. All immune cell counts remained high in CSF with respect to PB (Table 1) and no JCV copies were found; the IgG index was 4.16 . 
Table 1. Cellular Immunological Changes in Cerebrospinal Fluid (CSF) and Peripheral Blood (PB) During the Course of Progressive Multifocal Leukoencephalopathy in a Patient With Relapsing-Remitting Multiple Sclerosis Treated With Natalizumab

\begin{tabular}{lllll}
\hline Subset & Presentation & Week 6 & Week 15 & Week 31 \\
\hline CSF activated \%CD8 ${ }^{+}$ & $59.56 \%(14.93 \%)$ & $29.11 \%(3.44 \%)$ & $24.68 \%(2.27 \%)$ & $29.44 \%(22.64 \%)$ \\
PB activated \%CD8 ${ }^{+}$ & $30.28 \%(1.17 \%)$ & $20.92 \%(3.0 \%)$ & $27.00 \%(0.82 \%)$ & $3.64 \%(1.25 \%)$ \\
CSF activated \%CD4 ${ }^{+}$ & $30.22 \%(8.89 \%)$ & $74.38 \%(5.30 \%)$ & $77.84 \%(1.98 \%)$ & $68.33 \%(21.14 \%)$ \\
PB activated \%CD4 & $33.00 \%(8.89 \%)$ & $16.19 \%(17 \%)$ & $42.04 \%(0.99 \%)$ & $4.96 \%(2.34 \%)$ \\
CSF activated \%CD19+ & $0.35 \%(0.00 \%)$ & $16.67 \%(0.67 \%)$ & $24.71 \%(8.49 \%)$ & NP \\
PB activated \%CD19+ & $9.29 \%(7.80 \%)$ & $5.09 \%(39.21 \%)$ & $5.15 \%(3.22 \%)$ & $2.89 \%(27.62 \%)$ \\
CSF $\% C D 86^{+}$pDCs & $0.83 \%(100.00 \%)$ & $0.56 \%(33.93 \%)$ & $1.14 \%(40.00 \%)$ & $2.88 \%(83.33 \%)$ \\
PB \%CD86 ${ }^{+}$pDCs & $0.17 \%(98.96 \%)$ & $0.09 \%(83.84 \%)$ & $0.09 \%(61.54 \%)$ & $0.04 \%(54.29 \%)$ \\
\hline
\end{tabular}

NP: not performed.

\section{Discussion}

On withdrawal of NTZ and PLEX, the only $\mathrm{Gd}^{+}$lesions on cranial MRI were the PML lesions compatible with an inflammatory form of PML (PML-IRIS). Simultaneously, higher percentages of mature $\mathrm{CD} 86^{+} \mathrm{pDCs}$ and $\mathrm{CD} 8^{+} \mathrm{T}$ cells and lower percentages of $\mathrm{CD} 19^{+} \mathrm{B}$ cells and $\mathrm{CD}^{+}{ }^{+} \mathrm{T}$ cells were in CSF with respect to $\mathrm{PB}$. This finding was consistent with the described perturbance of memory and lower $\mathrm{CD}^{+} \mathrm{T}$ cells and $\mathrm{CD}_{19}{ }^{+} \mathrm{B}$ cells into the CNS could facilitate marginal zonelike B-cell homing in secondary lymphoid organs during NTZ treatment of JCV infection [3]. Lower $\mathrm{CD}^{+} \mathrm{T}$ cells and $\mathrm{pDCs}$ depletion have been reported in a histopathological study of NTZ-PML patients [4]. The influx of $\mathrm{CD}^{+}{ }^{+} \mathrm{T}$ cells and CD19 ${ }^{+}$ $B$ cells into the CSF after withdrawal of NTZ and PLEX coincided with control of JCV, providing evidence for the potential role of these cells in specific JCV responses. The CSF increase of $\mathrm{CD}^{+}$cytotoxic $\mathrm{T}$ cells known to be the main effector cells in viral infection could be implicated in the control of dissemination of JCV $[5,6]$. Autopsy of a patient of PML-IRIS showed that the inflammatory infiltrate was composed predominantly of $\mathrm{CD}^{+} \mathrm{T}$ cells in both parenchyma and perivascular cuffs, with fewer $\mathrm{CD}^{+}{ }^{+} \mathrm{T}$ cells and $\mathrm{CD} 20^{+} \mathrm{B}$ cells, which were confined to perivascular cuffs. These findings are in line with the first CSF, in which lower CSF JCV load and increased of CD8 ${ }^{+}$ $\mathrm{T}$ cells and $\mathrm{pDCs}$ was found.

Dendritic cells are central to the initiation and regulation of immune responses. In MS, circulating pDCs show reduced production of IL- 6 and IL-10 in response to herpes simplex virus type I, and also functional impairment of dendritic cells during NTZ was observed implying that their response to viral exposure could be impaired in MS [7, 8].

The posterior non-active PML-MRI lesions, undetectable JC viral load, and increased CSF IgG index suggest that plasma cells, the source of intrathecally produced IgG, including JCV-specific IgG, could contribute to resolution of PML, while lower CSF percentages of $\mathrm{CD}_{1} 9^{+} \mathrm{B}$ cell in some MS patients could predispose to development of PML.

PML lesions affect not only oligodendrocytes but also neurons [9]. Consequently, as in our patient, the possible infection of cortical pyramidal neurons in the left frontal lobules at the grey-white matter junction could increase neuronal excit- ability, leading to focal seizure. The clinical sequelae probably resulted from neuronal and axonal destruction by the JCV and/ or by inflammatory factors in the PML lesions, as observed in the last cranial MRI [10].

In conclusion, our case report illustrates that CSF-specific immune cells changes were present at the time of PML infection and during resolution. Furthermore, the MRI findings suggested that highly aggressive inflammatory PML lesions led to severe clinical deterioration as suggested by cortical neuronal and pontocerebellar axonal lesions.

\section{Acknowledgement}

The authors are thankful to this PML patient for consent to present her clinical, CSF and MRI information, to thank Haydee Goycochea for her excellent nursing care and to Gregg for helping in preparing the correct description of article.

\section{Competing Interest}

None of the authors declares competing interest.

\section{Author Contributions}

All co-authors have made a substantial contribution to the design, data collection and analysis of the research and the drafting of the manuscript, have reviewed, and accepted the contents of the manuscript prior to its submission.

\section{Financial Support}

No financial support was received for this article.

\section{References}

1. Weissert R. Progressive multifocal leukoencephalopathy. J Neuroimmunol. 2011;231(1-2):73-77. 
2. Khatri BO, Man S, Giovannoni G, Koo AP, Lee JC, Tucky B, Lynn F, et al. Effect of plasma exchange in accelerating natalizumab clearance and restoring leukocyte function. Neurology. 2009;72(5):402-409.

3. Planas R, Jelcic I, Schippling S, Martin R, Sospedra M. Natalizumab treatment perturbs memory- and marginal zone-like B-cell homing in secondary lymphoid organs in multiple sclerosis. Eur J Immunol. 2012;42(3):790-798.

4. del Pilar Martin M, Cravens PD, Winger R, Frohman EM, Racke MK, Eagar TN, Zamvil SS, et al. Decrease in the numbers of dendritic cells and CD4+ $\mathrm{T}$ cells in cerebral perivascular spaces due to natalizumab. Arch Neurol. 2008;65(12):1596-1603.

5. Du Pasquier RA, Stein MC, Lima MA, Dang X, JeanJacques J, Zheng Y, Letvin NL, et al. JC virus induces a vigorous $\mathrm{CD} 8+$ cytotoxic $\mathrm{T}$ cell response in multiple sclerosis patients. J Neuroimmunol. 2006;176(1-2):181-186.

6. Wuthrich C, Kesari S, Kim WK, Williams K, Gelman R, Elmeric D, De Girolami U, et al. Characterization of lymphocytic infiltrates in progressive multifocal leukoencephalopathy: co-localization of $\mathrm{CD} 8(+) \mathrm{T}$ cells with JCV-infected glial cells. J Neurovirol. 2006;12(2):116-
128.

7. Sanna A, Huang YM, Arru G, Fois ML, Link H, Rosati G, Sotgiu S. Multiple sclerosis: reduced proportion of circulating plasmacytoid dendritic cells expressing BDCA-2 and BDCA-4 and reduced production of IL- 6 and IL-10 in response to herpes simplex virus type 1. Mult Scler. 2008;14(9):1199-1207.

8. de Andres C, Teijeiro R, Alonso B, Sanchez-Madrid F, Martinez ML, Guzman de Villoria J, Fernandez-Cruz E, et al. Long-term decrease in VLA-4 expression and functional impairment of dendritic cells during natalizumab therapy in patients with multiple sclerosis. PLoS One. 2012;7(4): e34103.

9. Wuthrich C, Koralnik IJ. Frequent infection of cortical neurons by JC virus in patients with progressive multifocal leukoencephalopathy. J Neuropathol Exp Neurol. 2012;71(1):54-65.

10. Wuthrich C, Dang X, Westmoreland S, McKay J, Maheshwari A, Anderson MP, Ropper AH, et al. Fulminant JC virus encephalopathy with productive infection of cortical pyramidal neurons. Ann Neurol. 2009;65(6):742748 . 